\title{
Discurso e relações de poder na (re)construção da identidade profissional de professores de língua em uma comunidade de prática no ambiente digital
}

\author{
Selma Maria Abdalla Dias Barbosa \\ Universidade Federal do Tocantins \\ selmaabdalla@uft.edu.br \\ Patrícia Fabiana Bedran \\ Unesp - São José do Rio Preto \\ bedran@ibilce.unesp.br
}

\section{Resumo}

Este artigo tem como principal objetivo abordar questões referentes a discurso e relações de poder na (re)construção da identidade profissional de professores de língua em uma Comunidade de Prática em um ambiente virtual, tendo em vista a transitoriedade, a complexidade e a dinamicidade do objeto investigado. Trata-se de uma pesquisa qualitativa de cunho etnográfico que apresentou como procedimento metodológico um estudo de caso envolvendo dois professores em formação e uma professora formadora. Os resultados evidenciam posicionamentos de poder nas interações dos participantes, o que justifica a necessidade de abordagem temática desse complexo processo de (re)construção identitária nos cursos de graduação, de forma a contribuir de maneira mais significativa com a formação reflexiva e identitária dos futuros profissionais do curso de Letras.

Palavras-chave: Discurso. Poder. Comunidade de Prática. Formação de professor. Tecnologia.

\begin{abstract}
This article aims to address issues of discourse and power relations in the (re) construction of the professional identity of language teachers in a community of practice in a virtual environment, considering the transience, complexity and dynamics of the investigated object. This is a qualitative ethnographic research study, which presents the methodological approach of a case study involving two student teachers and a teacher educator. The results show power positions in the interactions of the participants, which justifies the need for a
\end{abstract}


thematic approach to this complex process of (re) construction of identity in undergraduate courses in order to more significantly contribute to the reflective and identity formation of future professionals in Modern Languages and Literature Courses.

Keywords: Discourse. Power. Community of Practice. Teacher formation. Technology.

\section{Considerações iniciais}

Este artigo, que traz como tema a formação da identidade do professor de língua, pretende explorar o discurso e as relações de poder na (re)construção de identidades profissionais, que extrapola o ambiente típico de sala de aula e permite o desenvolvimento de uma prática mais colaborativa dos participantes do processo interativo por meio da utilização de recursos tecnológicos - a plataforma Moddle. ${ }^{1} \mathrm{O}$ interesse em investigar e explorar a (re)construção de identidades em uma Comunidade de Prática (doravante $\mathrm{CdP}$ ) é justificado não apenas pela possibilidade do desenvolvimento de uma prática colaborativa e reflexiva, importantes no processo de (re)construção de identidades, mas também pelo desejo de investigar e trazer considerações a respeito da CdP, que tem sido timidamente explorada pelas pesquisas no âmbito educacional, de maneira geral, e, mais precisamente, na área de formação de professores (WENGER, 1998; WENGER, McDERMOTT; SNYDER, 2002; GIMENEZ; CAPRIOLI, 2014).

Tencionamos contribuir com os cursos de formação de professores na medida em que não apenas trazemos considerações e compreensões sobre a CdP na esfera educacional e buscamos refletir sobre o processo de (re)construção de identidade nesse contexto, mas também porque, de maneira mais pontual, sugerimos, com base nas reflexões propiciadas por meio deste estudo, articular uma proposta de reconceitualização dos projetos pedagógicos dos cursos de formação de professores de línguas. Seria desejável que os cursos de formação propiciassem o desenvolvimento de uma prática reflexiva que pudesse

\footnotetext{
${ }^{1}$ Moddle é uma plataforma virtual que permite a criação de cursos on-line, páginas de disciplinas, grupos de trabalhos e comunidade tendo em vista princípios e objetivos pedagógicos.
} 
levar os professores em formação inicial ao autoconhecimento (BARBOSA, 2014) no que diz respeito à sua identidade profissional, de forma que, ao se engajarem em situações tensas e desafiadoras, principalmente nos primeiros momentos de experiência na docência, pudessem fazê-lo com mais confiança e credibilidade em si mesmos e na formação que receberam na universidade.

A abordagem, no que diz respeito ao desenvolvimento de uma prática reflexiva sobre processos identitários, em cursos de formação de professores, bem como o avanço nos estudos desses processos, (re)construídos nas práticas sociais de linguagem, tornam-se, em grande parte dos contextos e das situações, desafios para os professores e/ou pesquisadores, tendo em vista a fluidez, a transitoriedade e a complexidade desse processo. Os desafios, decorrentes da complexidade do objeto de investigação, deveriam funcionar como impulsionadores de práticas formativas que contemplassem questões identitárias no âmbito educacional, condizentes com concepções e perspectivas mais contemporâneas na área de investigação.

Em uma perspectiva mais contemporânea, a identidade é vista como fragmentada, proteiforme ${ }^{2}$ e movediça, em oposição a uma definição fixa e unitária, usada para rotular pessoas, etnias, comunidade e cultura, independentemente das perspectivas teóricas e metodológicas que norteiam os estudos sobre identidades em diversos países. Uma singularidade ressalta: as relações de poder, conforme aponta Norton (2000). Exemplos de estudos citados pela autora encontram-se no Canadá (MORGAN, 1997), no Japão (DUFF; UCHIDA, 1997), na Inglaterra (LEUNG; HARRIS; RAMPTON, 1997), nos Estados Unidos (SCHECTER; BAYLEY, 1997) e na África do Sul (THESEN, 1997), cada um focando aspectos identitários com base em diferentes perspectivas, como, por exemplo, a ótica de Morgan, que se concentrou na perspectiva social da identidade, a de Duff e Uchida, concentrada na perspectiva sociocultural, a de Thesen, nos atos de fala, a de Scheter e Bayley, na perspectiva cultural, e a de Leung, Harris e Rampton, na etnicidade.

\footnotetext{
${ }^{2}$ Definição de proteiforme, segundo dicionário on-line de Português: adj. Que muda de forma frequentemente (como Proteu, deus da mitologia grega). Fonte: <http://www.dicio.com.br/proteiforme/>. Acesso em: 28 jul. 2012.
} 
De acordo com Norton (2000), todos os pesquisadores citados chegaram a um consenso: que a construção de identidades deve ser entendida por meio das relações de poder entre os aprendizes de língua estrangeira (doravante LE) ou de segunda língua (doravante L2) e falantes da língua-alvo. A essas relações de poder acrescentamos aquelas que acontecem entre falantes de uma mesma língua, que almejam aprender a ensinar uma LE em contexto virtual e/ou presencial, como é o caso dos sujeitos participantes deste estudo. Quando ressaltamos a relevância das relações de poder, tanto na aprendizagem e no ensino de línguas quanto na formação de professores, entendemos que elas deveriam ser estudadas e analisadas sob lentes críticas, como são os estudos desenvolvidos por Freire (1970; 1993), Giroux (1988; 1999) e Simon (1987; 1992), que concebem o ensinar línguas como um ato social e fortemente politizado (NORTON, 2000).

Essas e outras pesquisas que abordam posições críticas em relação às ações interativas (CORACINI, 2007) e a posicionamentos de poder no discurso (FOUCAULT, 1979; NORTON, 2000; FAIRCLOUGH, 2003; CLARKE, 2008; TRENT; LIN, 2010; LEFFA, 2013), bem como os pressupostos teóricos da Linguística Aplicada indisciplinar ou antidisciplinar (MOITA LOPES, 2006), embasam teoricamente este artigo, que traz um recorte da pesquisa de doutorado de Barbosa (2014). Trata-se de uma pesquisa qualitativa (MOITA LOPES, 1996), interpretativista (ERICKSON, 1986; FETTERMAN, 1998; BURNS, 1999; ANDRÉ, 2000, 2005) e de cunho etnográfico e longitudinal, cujos instrumentos geradores de dados foram os discursos (CORACINI, 2003) postados pelos professores em formação inicial em uma CdP, criada no início de 2010 e que se estendeu até final de 2011 no âmbito das disciplinas de Estágio Supervisionado de Inglês I, II, III e IV do curso de Licenciatura em Letras de uma universidade pública do Estado do Tocantins.

Para o desenvolvimento desta pesquisa foi adotado o estudo de caso como formato metodológico em função da natureza do trabalho colaborativo que se configurou na $\mathrm{CdP}$, na qual se constatou um forte elo de suporte mútuo entre os participantes bem como de compartilhamento tanto de realizações quanto de frustrações entre eles. A ênfase da investigação recai na transitoriedade do fenômeno investigado, isto é, o objeto na sua essência complexa, dinâmica e 
transitória (NUNAN, 1992; ANDRÉ, 1995), que é a identidade profissional do professor de línguas em formação.

Com o intuito de abordarmos as relações e os posicionamentos de poder que se instauraram e influenciaram no processo de (re)construção da identidade do profissional em formação inicial em uma $\mathrm{CdP}$, em contexto virtual, trazemos referenciais teóricos sobre comunidade de prática e identidade, discurso, poder e investimento, bem como apresentamos informações sobre o contexto e a metodologia de pesquisa e, na sequência, realizamos a análise e a discussão dos dados. Por fim, apresentamos as considerações finais sobre as relações de poder no processo de construção de identidade.

\section{Afinal, o que é comunidade de prática?}

Comunidade de prática não é conceito novo, posto que já se tinha uma noção de comunidades sociais há muito tempo, quando, por exemplo, os primitivos moravam em cavernas e se aglomeravam em volta de fogueiras para discutir estratégias de caça, os formatos e os tamanhos das flechas ou quais raízes seriam comestíveis (WENGER; McDERMOTT; SNYDER, 2002). Essa forma de organização se perpetuou também na Idade Média e prosseguiu até os dias atuais, e, segundo os autores, continuou a se proliferar na contemporaneidade de modo a alçar todos os aspectos da vida humana, visto que todos nós, seres humanos, de alguma forma pertencemos a várias comunidades ou já tivemos a experiência de pertencer a uma delas: trabalho, escola, casa ou lazer.

Indo ao encontro dessas formas de organização coletiva, o conceito de CdP apresentado por Wenger (1998) refere-se a um grupo que compartilha e partilha de uma prática e interage para aperfeiçoá-la. A intencionalidade do trabalho e a necessidade de aperfeiçoamento de uma prática torna a CdP singular, diferenciando-a de outros tipos de comunidades, descritas anteriormente. A noção de CdP ainda não é um consenso entre seus estudiosos, cujos questionamentos recobrem desde a sua criação até sua manutenção e gerenciamento. A extensão da CdP para diversas áreas gera ainda mais indagações sobre sua formação, constituição, manutenção e características, uma vez que acreditamos que, apesar de consideradas as definições trazidas por Wenger (1996) e 
suas características base como ponto de partida, a especificidade de cada área é responsável por (re)configurar de maneira muito peculiar a comunidade, de acordo com suas necessidades e particularidades.

Quando pensamos no âmbito educacional, isso não é diferente; assim, surgem diversas indagações, dentre as quais buscamos ressaltar e repensar neste estudo, tendo em vista os objetivos deste trabalho, aquelas relacionadas à definição de $\mathrm{CdP}$ e às relações de poder estabelecidas em uma comunidade: O que é uma Comunidade de Prática para e no contexto educacional? Como se dão as relações de poder dentro dessa comunidade?

Não temos a pretensão de responder a esses questionamentos e trazer uma solução no mínimo ingênua para questões tão novas e complexas, como é o uso das CdPs para e no contexto de formação de professores e/ou no ensino e aprendizagem de línguas, que, por sua vez, se faz somar à complexidade do fenômeno das relações de poder na sociedade por meio da linguagem e do conhecimento na contemporaneidade, o que, pode-se dizer, vem sendo discutido por estudiosos renomados da Linguística Aplicada em congressos e seminários nacionais e internacionais (MEDEIROS, 2005; BEDRAN, 2012; BUCKLEY; DU TOIT, 2010; PINO-SILVA; MAYORA, 2010; GIMENEZ; CAPRIOLI, 2014). No entanto, tentamos entender e compartilhar essas inquietações e, consequentemente, trazer à esteira dessas discussões algumas questões que surgiram no percurso deste estudo.

Primeiramente vamos discutir a definição de CdP com base em construtos teóricos de Wenger e seus colaboradores, para quem CdPs "são grupos de pessoas que compartilham uma preocupação, os mesmos problemas ou uma paixão sobre determinado tópico, e também aprofundam seus conhecimentos e experiência na área através de interações contínuas"3 (WENGER; McDERMOTT; SNYDER, 2002, p. 4). Os membros da CdP não necessariamente trabalham juntos diariamente, mas se encontram - presencial e/ou virtualmente - porque valorizam suas interações, por meio das quais podem (co)construir

\footnotetext{
${ }^{3}$ Communities of Practice are groups of people who share a concern, a set of problems, or a passion about a topic, and who deepen their knowledge and expertise in this area by interacting on an ongoing basis.
} 
conhecimentos, compartilhar informações, visões, experiências e conselhos e se ajudar na resolução de seus problemas.

Esse grupo de pessoas (co)constrói e acumula conhecimentos, pois elas estão ligadas informalmente pelo valor que atribuem em aprender juntas. Esse valor não é meramente uma questão de motivação instrumental de trabalho, "mas também um acúmulo de satisfação pessoal, pois os colegas conhecem as perspectivas uns dos outros, além de terem um sentimento satisfatório de pertencimento a um grupo de pessoas interessantes" (WENGER; McDERMOTT; SNYDER, 2002, p. 5). Ao fazer uma análise aprofundada sobre a noção de CdP em seus estudos, Wenger (1998) e posteriormente Clarke (2008) afirmam tratar-se de um grupo cuja coerência como uma comunidade é definida e composta por três dimensões: compromisso/engajamento mútuo - mutual engagement, empreendimento partilhado - joint enterprise - e repertório compartilhado - shared repertoire. A primeira dimensão, a do compromisso/engajamento mútuo, refere-se à participação em um empreendimento ou prática cujos significados são negociados entre os participantes, ou seja, a prática só existe enquanto houver indivíduos comprometidos com determinadas ações ou com ideias comuns.

A segunda dimensão, a do empreendimento partilhado, relaciona-se ao foco da atividade que une os membros de uma comunidade, ou seja, o que é constantemente renegociado por cada um dos membros da $\mathrm{CdP}$, criando, assim, possibilidades mútuas entre os participantes. A terceira dimensão, o repertório compartilhado, por sua vez, diz respeito aos recursos comuns para a criação de sentido que resultam da participação em empreendimento conjunto, quer dizer, rotinas, instrumentos, metodologias, histórias, símbolos, conceitos e ações adotados ao longo de sua existência. Segundo Clarke (2008), o engajamento/compromisso mútuo significa uma forma de superar as diferenças e as diversidades dentro da comunidade, sem, contudo, implicar homogeneidade entre os participantes, pois, além das diferenças que os indivíduos trazem, os membros de uma comunidade podem ter papéis distintos e ofertar contribuições complementares para o empreendimento empresarial ou educacional em questão. Além das três dimensões cruciais para a formação de uma $\mathrm{CdP}$, já mencionadas, Wenger (1998) também explora a noção de construção de identidades como uma experiência de pertencimento a um grupo de pessoas de 
identidades proteiformes, que se justifica a partir de três funções: engajamento - engagement, imaginação - imagination e alinhamento alignment.

Por meio do engajamento, "o indivíduo estabelece e mantém ações discursivas e negocia significados, posto que o engajamento nos permite investir no que queremos fazer e nas nossas relações de poder com outras pessoas (o que podemos ou não fazer e/ou dizer), ganhando um 'senso' vivo de quem somos" (WENGER, 1998, p. 192). ${ }^{4}$ A imaginação, por seu turno, refere-se à criação de imagens do mundo e de nossos lugares dentro da sociedade em que atuamos por meio de nossas próprias experiências através do tempo e do espaço. Alinhamento, por sua vez, coordena as atividades do indivíduo com estruturas e empreendimentos mais amplos, permitindo à identidade de um grupo maior se tornar parte da identidade individual do participante. Vale ressaltar ainda que Wenger (1998) define quatro componentes fundamentais para uma teoria social da aprendizagem, as quais vão ao encontro dos pressupostos de formação de CdPs e de (re)construção identitária. Nomeadamente são: (a) significado, que traduz a capacidade e a necessidade que temos de encontrar sentido para o mundo, pois aprendemos quando procuramos um sentido para nossa existência individual e coletiva no mundo; (b) a prática, que exprime a vivência partilhada de recursos e perspectivas que mantêm nosso envolvimento mútuo na ação, isto é, aprendemos quando fazemos; (c) comunidade ou configuração social, em que definimos nossas iniciativas e pela qual nossa participação é reconhecida; em outros termos, aprendemos construindo um sentido de pertença; e (d) a identidade, que surge da forma como a aprendizagem transforma quem somos e como constrói histórias pessoais de quem somos no contexto das nossas comunidades, ou, dito de outro modo, aprendemos por meio do processo de construção da nossa própria identidade.

Para o autor, esses componentes estão interligados e se definem mutuamente, quer dizer, os interagentes do grupo desenvolvem relacionamentos de amizade e engajamentos mútuos e são eles, os participantes, quem estabelecem as formas de interação e

\footnotetext{
${ }^{4}$ No original: As we build communities of practice through this process, we work out our relations with each other and with the world, and we gain a lived sense of who we are.
} 
as negociações de significados para que ocorra a aprendizagem. Para Wenger, McDermott e Snyder (2002, p. 5), "eles podem até desenvolver um senso comum de identidade através do sentimento de pertença ao grupo social, isto é, eles formam uma comunidade de prática" e, consequentemente, aprendem com e no processo de reconstrução identitária por intermédio das relações de poder.

Durante a análise do corpus, sentimos a necessidade de ampliar o aporte teórico proposto por Wenger (1998) no sentido de pontuarmos duas situações distintas nas interações - a teoria e a prática; em outras palavras, a identidade no discurso e a identidade na prática. Na primeira situação o sujeito se faz no e pelo discurso, e no segundo momento o sujeito se faz em suas ações. E, em consonância com Varghese et al. (2005), para se entender melhor tanto o ensino quanto seus atores - os professores e suas identidades, é preciso focar nossa atenção em ambos os aspectos ou abordagens de análise, que são: identidade-no-discurso e identidade-em-prática.

À luz de suas teorias, entendemos que identidade-em-prática se refere à participação do indivíduo na comunidade social, ou seja, a investigação obedece a uma abordagem orientada à (re)construção da identidade profissional do professor nas suas atividades, tarefas e experiências com e no ensino por meio da linguagem. $\mathrm{O}$ outro aspecto de (re)construção da identidade do professor, na perspectiva da identidade-no-discurso, tem como pressuposto que a identidade é (re)construída e constitutiva do discurso, ou, dito de outra maneira, ela se dá principalmente por meio da linguagem, como bem explica a teoria pós-estruturalista, segundo a qual a construção da identidade é evidenciada a partir de negociações nas relações e nas posições de poder do sujeito do discurso (VARGHESE et al. 2005).

A CdP desta pesquisa, que teve como suporte para seu desenvolvimento a plataforma Moodle, foi planejada para que os discentes da disciplina Estágio Supervisionado de Língua Inglesa pudessem se engajar em discussões sobre tema ou área do mesmo interesse ou paixão (WENGER, 1998), como, por exemplo, planejamento de aulas, realização e reflexão de atividades dinâmicas lúdicas com relação ao conteúdo linguístico, compartilhamento de suas práticas de estágio e/ou simplesmente para expressar suas emoções relacionadas às suas experiências em campo de estágio ou na produção dessas atividades. Ao idealizarmos e criarmos essa $\mathrm{CdP}$, o que se deu 
segundo os pressupostos de Wenger (1998), buscamos integrar em nossas metodologias de análise da (re)construção de identidade profissional dos professores em formação as duas propostas de abordagem de Varghese et al. (2005). Em outras palavras, objetivamos lançar um olhar crítico tanto sobre as identidades-na-ação quanto sobre as identidades-no-discurso, pois, como nos afirma Reis (2011, p. 34), "como um membro das comunidades de prática, um indivíduo pode potencialmente (re)criar sua história em novas subjetividades, tanto através do discurso quanto da ação".

No decorrer de nossa investigação, que tinha como embasamento teórico os preceitos trazidos por Wenger (1998), deparamo-nos com a ausência de aporte teórico sobre as relações de poder e assimetria que ocorrem em uma comunidade virtual, como, por exemplo, o poder do discurso do professor-formador em relação ao dos professores em formação. Essa e outras inquietações e/ou situações pontuais no que se refere às negociações de identidades dentro da $\mathrm{CdP}$ foram ao encontro dos estudos e apontamentos de Trent e Lim (2010), que fazem menção às críticas sofridas pela teoria de Wenger (1998) em relação à construção de identidades em ação nas CdPs. De acordo com Creeze (2005), citado pelos autores, o quadro teórico de Wenger (1998) no que se refere à construção da identidade está sendo alvo de críticas porque não desenvolve uma teoria coerente com a linguagem em uso (TRENT; LIM, 2010, p. 164). ${ }^{6}$ Ademais, ainda de acordo com os autores, Wenger (1998) oferece uma visão "benigna" de comunidade, e um dos pontos que justifica tal afirmativa é seu fracasso em teorizar adequadamente as relações de poder existentes nas comunidades.

Assim como ocorreu no trabalho de Trent e Lim (2010), este trabalho, como já mencionamos, também sofreu com essa limitação de aporte teórico que oferecesse sustentação às discussões mais críticas de uso da linguagem e/ou posições de poder e lugar ou nicho de quem pronuncia seu discurso nas $\mathrm{CdPs}$, tornando necessário que nos

${ }^{5}$ As a member of communities of practice, an individual can potentially restory him Vherself into new subjectivities through both discourse and action.

${ }^{6}$ Wenger (1998) framework for understanding identity construction has, however, been criticized for failing to develop a coherent theory of language in use. 
apoiássemos também no modelo de (re)construção identitária de Fairclough (2003, p. 164), que, em seus próprios termos, diz: “Aquilo com o que as pessoas se comprometem nos textos é parte importante de como elas identificam a si mesmas. ${ }^{7}$ Recorremos ainda às noções de poder e investimento cunhadas por Norton (2000) e Leffa (2013), promovendo, assim, uma integração dos quadros teóricos de Wenger (1998), Norton (2000), Fairclough (2003) e Leffa (2013), no intuito de proporcionarmos uma pesquisa baseada na perspectiva inter e transdisciplinar proposta nos estudos mais recentes da Linguística Aplicada. Na próxima seção introduziremos concepções teóricas sobre discurso, poder e investimento que assumimos no decorrer deste estudo.

\section{Poder, investimento e discurso}

Para entendermos melhor a ressignificação do termo identidade que está sendo proposta neste texto, precisamos perpassar por algumas noções de termos que estão diretamente relacionados ao complexo processo de (re)construção de identidades profissionais, que são: poder e investimento, na perspectiva de Norton $(2000)^{8}$ em sua pesquisa sobre identidade e aprendizagem de línguas, na qual a autora, em um estudo longitudinal, dá ênfase à construção de identidades de mulheres imigrantes no Canadá durante o processo de aquisição da língua inglesa como segunda língua.

A adoção e a definição desses dois construtos teóricos - poder e investimento - também nos são relevantes, e para melhor entendimento destes nos dedicaremos às suas definições, porém de forma a relacioná-los ao contexto de formação inicial de professores de línguas e suas implicações na (re)construção de suas identidades profissionais por meio dos posicionamentos de poder. Para Norton (2000), estudiosos da área de Aquisição de Segunda Língua (SLA)

\footnotetext{
${ }^{7}$ What people commit themselves to in texts is an important part of how they identify themselves, the texturing of identity.

${ }^{8}$ Entendemos que Norton (2000) desenvolve o termo poder baseado em concepções e estudos desenvolvidos anteriormente por Bourdieu e Passeron (1991) e Foucault (1979).
} 
esforçam-se para entender e conceituar a relação entre aprendizes de língua e o mundo social, mas, em geral, apresentam uma distinção entre ambos - língua e social - de forma artificializada, o que ocorre "porque eles não desenvolvem uma teoria de compreensão de identidade, a qual integra o aprendiz de língua e o contexto de fala da língua-alvo" (NORTON, 2000, p. 4). ${ }^{9}$ A autora também acredita que eles muitas vezes não questionam, por exemplo, como as relações de poder no mundo social influenciam nas interações sociais entre os aprendizes de segunda língua e falantes da língua-alvo.

Para a autora, poder compreende:

[...] relações socialmente construídas entre indivíduos, instituições e comunidades, através das quais recursos simbólicos e materiais numa determinada sociedade são produzidos, distribuídos e validados. Por recursos simbólicos, eu me refiro a recursos como língua(gem), educação e amizade, enquanto uso os termos recursos materiais para incluir bens de capital, bens imóveis e dinheiro (NORTON, 2000, p. 7). ${ }^{10}$

De acordo com Bourdieu e Passeron (1991), o poder pode ser conquistado por meio das ferramentas culturais que garantem maior poder a um indivíduo ou a um grupo de indivíduos. Entre essas ferramentas estão o conhecimento adquirido, como, por exemplo, uma segunda língua ou LE, garantindo a esse indivíduo uma posição social privilegiada ou status diferenciado em relação a outro indivíduo monolíngue, quer dizer, essa ferramenta simbólica, a aprendizagem de outra língua, pode servir para que os indivíduos transponham uma barreira social entre uma posição inferior e outra de maior prestígio. Para o contexto de formação de professores de línguas, isso pode

${ }^{9}$ Because they have not developed a comprehensive theory of identity that integrates the language learner and the language learning context.

${ }^{10}$ I use the term 'power' to reference the socially constructed relations among individuals, institutions and communities through which symbolic and material resources in a society are produced, distributed and validated. By symbolic resources I refer to such resources as language, education and friendship, while I use the term material resources to include capital goods, real estate and money. 
significar ascensão social por meio de garantia de trabalho e construção e desenvolvimento de carreira.

Para além dessa discussão sobre poder de Bourdieu e Passeron (1991), Foucault (1979), Simon (1992) e Norton (2000) assumem uma concepção de poder como algo mutável e não monolítico, ou seja, poder não é algo que possa ser fisicamente possuído e adquirido invariavelmente, mas, ao contrário, está intrinsecamente relacionado às mudanças de valores sociais, assim como o capital cultural ${ }^{11}$ muda com o contexto histórico, pressupondo, então, uma constante negociação entre os indivíduos de certa comunidade. Além disso, concordamos com os apontamentos de Norton (2000) ao evidenciar que "poder" não opera somente em macrocontextos, como, por exemplo, no sistema educacional ou político do país, na cidade, no bairro, etc., mas também podemos encontrá-lo no nível dos microcontextos, nas interações do dia a dia das pessoas no trabalho, nas escolas, nas igrejas, no mercado, nas reuniões de bairro e assim por diante, pois nessas interações cotidianas encontramos pessoas que apresentam diferentes tipos e níveis de acesso aos capitais culturais.

No entanto, as relações de poder não são fixas nem quantitativamente predeterminadas, mas sim geradas mutuamente nas relações interpessoais e intergrupais. Ademais, apresentam características contraditórias, pois, ao mesmo tempo em que atuam como instrumento motivador para capacitar a aprendizagem, podem também constranger ou reprimir as negociações e (re)construções de identidades nos embates de sala de aula ou até mesmo em CdPs virtuais. Em outras palavras, as relações de poder podem ser tanto coercitivas como colaborativas no processo de interação na/pela linguagem (CUMMINS, 1996), e, nessa direção, torna-se coerciva

${ }^{11}$ Segundo Bourdieu e Passeron (1982), citados por Sousa (2011, p. 108), "capital cultural se refere às ferramentas culturais que garantem maior poder a um indivíduo ou a um grupo de indivíduos. Entre essas ferramentas estão o conhecimento adquirido e a posição social ou status, que podem manter um indivíduo em sua posição privilegiada ou servir para que indivíduos transponham uma espécie de barreira social entre uma posição inferior e outra de maior prestígio. Tais ferramentas são culturais, segundo os autores, porque foram culturalmente construídas, através da atribuição de valores feita por cada cultura". 
quando o poder é exercido por um indivíduo, grupo ou país dominante sobre outros com menos poder com o fim de manter uma divisão desigual de recursos em uma sociedade, como, por exemplo, a priorização unificada da norma culta, isto é, da língua padrão nas escolas brasileiras, como único e excludente meio de comunicação oral e escrito. Contudo, as relações de poder são colaborativas quando se configuram mais como formas de empoderamento do que como forma de marginalização.

Para dar conta da complexa relação entre "poder", "identidade"e "aprendizagem de línguas", ao que acrescentamos também formação de professores, Norton (2000, p. 10) se vale de um novo termo - "investimento" -, que, segundo ela, "mostra as relações sociais e históricas construídas nos relacionamentos entre os aprendizes e a língua-alvo e seus desejos frequentemente ambivalentes em aprender e praticar isso". Entendemos que quando um aprendiz investe na aprendizagem de outra língua ele o faz com a intenção de adquirir uma cadeia mais ampla de recursos simbólicos e materiais, os quais irão aumentar o valor de seus capitais culturais. Quando os aprendizes investem em seus desejos de aprender língua o fazem porque "têm a esperança de ter um bom retorno nos seus investimentos - um retorno que dará a eles acesso a recursos ou valores anteriormente inalcançáveis" (NORTON, 2000, p. 10).

Norton (2000) esclarece-nos que as concepções de motivação e investimento são parecidas, podendo nos levar em alguns momentos a perguntar se o interesse do aprendiz em ampliar seus recursos materiais e simbólicos, e, com isso, conquistar mais bens culturais, não seria também uma forma de motivação instrumental. Apesar da aparente semelhança, que pode ocasionar dúvidas como essa, as duas concepções, segundo a autora, diferem no sentido de que a motivação instrumental possui propósitos unitários, fixos e investiga um aprendiz de línguas descontextualizado social e historicamente, aquele que almeja simplesmente o acesso a recursos materiais que falantes da língua-alvo possuem. Por outro lado, a noção de investimento empregada por Norton (2000) entende que o aprendiz de línguas tem um complexo e múltiplo desejo social e histórico, estando aí pressuposto que quando aprendizes de língua falam não estão simplesmente trocando informações com falantes da língua-alvo, mas estão constantemente organizando e reorganizando o senso de quem 
são e como se relacionam com o mundo social. Além disso, Norton (2000, p. 11) afirma que "o investimento na língua-alvo também é um investimento na própria identidade do aprendiz de línguas, uma identidade a qual está constantemente mudando no decorrer do tempo e espaço". 12

À luz desses estudos da autora, entendemos que a noção de investimento é um avanço nos estudos de motivação, sendo os estudos de Gardner e Lambert (1972) também caros às áreas de aquisição de segunda língua, de ensino e aprendizagem de LE, como também para a área de formação de professores de línguas. Porém, a noção de investimento cunhada por Norton (2000) nos traz algo mais dinâmico e processual, sendo capaz de abranger de forma mais significativa os estudos de (re)contrução identitária pós-estruturalista (MANTERO, 2007) propostos nesta investigação, como mostraremos no decorrer do texto. Vale ressaltar aqui que essa noção de investimento, traçada por Norton (2000), assemelha-se aos apontamentos e estudos de Urzúa e Vásquez (2008) sobre investimento na construção da identidade profissional a partir das relações e das ações sociais imbuídas de poder. Estes acrescentam ainda a necessidade de observar essas interações não só como reflexões pertinentes para uma conscientização do presente, mas, também, com base em sua relevância na composição de eventos futuros, em uma perspectiva de construção identitária prognóstica. Tal como os autores, acreditamos na relevância desse tipo de reflexão e de análise do discurso voltado para o futuro, de forma a propiciar aos professores a possibilidade de interpretação de suas experiências iniciais tendo em vista uma projeção futura para que possam "[...] imaginar o tipo de professor que querem tornar-se, e usar seus anos de formação como um meio de projetarem em uma autoidentidade futura de professor" (URZÚA; VÁSQUEZ, 2008, p. 44). ${ }^{13}$

Assim como o fazem Norton (2000), Urzúa e Vásquez (2008), Leffa (2013) também traz em seus estudos a análise das identidades

12 Tradução de: Thus an investment in the target language is also an investment in a learner's own identity which is constantly changing across time and space (NORTON, 2000, p. 11).

${ }^{13}[. .$.$] to imagine the kind of teacher they want to become, and to use their$ formative years as a means to project a designated sense of self as teachers. 
considerando uma visão mais crítica, de modo que sejam contempladas as relações de poder que nelas se instauram, entendendo que a construção da identidade pode ser descrita de várias perspectivas, preferindo, no entanto, focalizá-la com base em três ângulos: (1) dimensão geográfica - destaca a possibilidade de expansão e contração espacial da identidade, na medida em que inclui numa direção e exclui na outra; (2) dimensão histórica - mostra como o conceito de identidade se diluiu com o tempo, esfarelando-se de um bloco único e rígido até formar uma nuvem de resíduos que se desmancha no ar; e (3) dimensão dialética - a identidade situada num jogo de confrontos que se constrói para legitimar quem pode e quem não pode ser incluído num determinado grupo (LEFFA, 2013).

Neste estudo damos ênfase à dimensão dialética, ou seja, da diferença entre si e o outro nas relações e nas atitudes, dinâmica, na qual, segundo Leffa, (2013, p. 69), se percebe o "desejo histórico de prevalecer sobre o outro", ou seja, nas relações de poder executadas primordialmente por meio da linguagem/discurso o que observamos "em geral é uma tentativa de dominação sobre o outro, procurando convencê-lo de algum modo de que ele é um ser inferior, quer seja pela cor, pela raça, pela nacionalidade ou simplesmente pelo nível de pobreza" (LEFFA, 2013, p. 70), ou ainda pelos diferentes tipos e níveis de bens simbólicos e/ou materiais adquiridos pelos agentes interacionais daquele contexto específico. Como também constatamos, há um consenso entre Norton (2000); Urzúa e Vásquez (2008) e Leffa (2013) sobre a relevância das relações de poder nas negociações identitárias dos interagentes, primordialmente por meio do uso da linguagem/discurso.

Tendo em vista que a negociação identitária se dá por meio do discurso, vimos a necessidade de apresentar uma noção de discurso assumida no percurso deste estudo, e o fazemos em conformidade com Clarke (2008), para quem, assim como cultura, trata-se de um dos termos mais usados e definidos na sociedade e nas discussões educacionais e, por isso, muitas vezes, pela amplitude do objeto, sua definição torna-se uma tarefa desafiadora. De acordo com Clarke (2008), em alguns momentos nos referimos a discursos de conhecimentos específicos de uma área, como, por exemplo, o discurso educacional, o discurso gerativista e, em outros, a discursos de comunidades sociais específicas, como o discurso feminista, o dos 
professores, o dos advogados, etc. No entanto, podemos afirmar que discurso tanto pode referir-se a comunidades sociais como também a conhecimentos específicos de certa área científica (CLARKE, 2008). Corroboramos o posicionamento de Clarke (2008) quanto ao assunto, uma vez que para ele é necessária a manutenção de uma abertura e flexibilidade quanto à concepção do discurso, pois [...] "o valor do termo é ser uma ferramenta heurística, similar à cultura, e esse valor é susceptível de ser perdido se tentamos fixar um significado do termo com precisão (CLARKE, 2008, p. 16). ${ }^{14}$

Tomando então os devidos cuidados para não cunharmos uma definição rígida, unitária e inflexível de discurso, procuramos sempre ter um olhar heurístico em relação ao objeto. Dito isso, entendemos que discurso empregado neste estudo implica um modo de ação no mundo, assim como também significa uma expressão ou forma de representação desta ação social. Isso implica uma intrínseca relação constitutiva de linguagem e sociedade, entre a palavra e os múltiplos níveis: no nível do conhecimento e das crenças, no das relações sociais em comunidades, como, por exemplo, gênero, classe ou instituições, e também no nível das identidades sociais (FAIRCLOUGH, 1993; CLARKE, 2008). Em outros termos, ao mesmo tempo em que o homem produz e transforma o discurso, ele também é transformado por meio das constantes (re)negociações identitárias que ocorrem nas interações.

\section{Metodologia de investigação}

Este estudo, de natureza qualitativa (MOITA LOPES, 1996), interpretativista (ERICKSON, 1986; FETTERMAN, 1998; BURNS, 1999; ANDRÉ, 2000 e 2005) e de cunho etnográfico, apresenta como contexto mais amplo as disciplinas de Estágio Supervisionado de Língua Inglesa e Literatura I, II, III e IV do curso de Licenciatura em Letras de uma universidade federal. Os dados foram coletados na plataforma Moodle, que serviu como suporte tecnológico para a

\footnotetext{
${ }^{14}[\ldots]$ the value of the term is a heuristic tool, similar again to culture, and that value is likely to be lost if we try to pin the meaning of the term down too precisely.
} 
configuração de uma $\mathrm{CdP}$ - grupo de pessoas que, na definição de Wenger, McDermott e Synder (2002), compartilham preocupações e paixões e constroem conhecimento por meio de interações contínuas. $\mathrm{Na}$ função de suporte, a plataforma possibilitou a realização de atividades e a interação entre os participantes, que, por meio do compromisso/engajamento mútuo, empreendimento partilhado e repertório compartilhado (WENGER, 1988), possibilitaram a construção de uma CdP.

Essa comunidade tinha como principal objetivo aperfeiçoar a formação profissional desses futuros professores, dando continuidade ao trabalho realizado presencialmente nas disciplinas de Estágio. Nesse ambiente de formação, os discentes discutiam questões teóricas com base na leitura sugerida pelo formador, buscando relacionar teoria e prática, compartilhavam ideias, experiências e inquietações relacionadas aos estágios que estavam realizando - regência de aulas em língua inglesa - e tinham abertura para fazer relatos e reflexões sobre suas emoções, decepções, frustrações e paixões no que se refere à sua formação e atuação profissional. O professor formador atuava como mediador desse processo, instigando a prática reflexiva, sugerindo leituras e dando suporte aos professores em formação.

No primeiro ano de pesquisa, as interações ocorreram motivadas pelo engajamento mútuo, pelo senso de responsabilidade e pelo compartilhamento; porém, nos dois últimos semestres do segundo ano de coleta de dados, observamos uma diminuição significativa de postagens e da participação dos interagentes. Como tentativa de recuperar a motivação, os formadores resolveram atribuir nota $(1,0)$ a quem participasse significativamente da CdP. Uma vez que a participação na plataforma estava prevista como parte das atividades das disciplinas de Estágio, todos os professores em formação passaram a ser avaliados pela participação ao longo do processo, juntamente com as demais atividades previstas no cronograma da disciplina.

A diminuição das postagens não inviabilizou o desenvolvimento e a formação da $\mathrm{CdP}$, que continuou apresentando como base o engajamento, o empreendimento e o repertório compartilhado. Porém, o formador, sentindo necessidade de uma participação mais assídua e central dos discentes, tendo em vista os 
níveis de participação dos envolvidos, ${ }^{15}$ apresentados por Wenger, McDermott e Snyder (2002), optou por fazer atribuição de pontuação, uma vez que isso poderia funcionar como um fator motivacional que culminaria em um nível mais central e ativo de participação. Ademais, os discentes são avaliados por todas as outras tarefas realizadas na disciplina. Assim, atribuir uma nota para essa atividade seria uma forma de valorizar o empenho e o engajamento dos participantes, como acontece nas demais atividades, que ajudam a compor a média final do discente na disciplina. A atribuição de nota gerou, conforme esperado, uma participação mais central dos envolvidos, delineando a configuração desta $\mathrm{CdP}$, que apresentou mais participantes exercendo um papel central, ao realizar todas as atividades de forma desejável pelo formador.

As tarefas realizadas na plataforma eram diversificadas e exigiam uma participação assíncrona dos membros: (1) fóruns de discussão, para dar continuidade às compreensões e às reflexões sobre os textos lidos e discutidos durante a aula e direcionar para aspectos mais pontuais, que deveriam ser desenvolvidos, com base na relação teoria e experiência prática de estágio vivenciada pelos participantes; (2) resenhas de textos teóricos, sugeridos com base nas experiências práticas relatadas na plataforma e/ou em sala de aula; (3) participação em sessões temáticas sobre "tornar-se" professor de LE, "ser" professor de LE e "sentir-se" professor de LE, para que pudessem expor suas concepções, emoções, frustrações e sentimentos com relação à docência.

Os instrumentos de coleta de dados são registros das interações no Moodle e uma entrevista realizada individualmente, ao final da pesquisa, com os dois participantes. Os participantes focais são Ricardo e Laura, ${ }^{16}$ alunos regularmente matriculados no curso de Licenciatura em Letras nos anos de 2011 e 2012, período em que se

15 De acordo com Wenger, McDermott e Snyder (2002), a CdP pode ser formada pelos participantes centrais/núcleo, que participam ativamente; os ativos, que participam ocasionalmente, e os periféricos, que raramente participam. Os participantes podem se deslocar nesses três níveis, central/núcleo, ativo e periférico, a depender de inúmeros fatores como tempo, motivação e atividade a ser desempenhada.

${ }^{16}$ Os nomes dos participantes são fictícios para preservar sua identidade. 
deu a coleta de dados. À época, o curso oferecia habilitação dupla: Português e Inglês, sem dar aos professores em formação a opção por uma das duas licenciaturas. A opção de investigar apenas dois participantes baseou-se na impossibilidade de trabalharmos com todos os alunos matriculados nas disciplinas de Estágio (em torno de 25 alunos) e na necessidade de realizarmos uma análise mais aprofundada, com número restrito de participantes. Ricardo e Laura foram escolhidos devido à participação ativa na plataforma, à realização, com afinco e engajamento, de grande parte das atividades sugeridas e à prontidão em participar da entrevista, que não era obrigatória. Segue o quadro com informações relevantes a respeito dos participantes.

Quadro 1. Descrição dos participantes

\begin{tabular}{|l|c|c|}
\cline { 2 - 3 } \multicolumn{1}{l|}{} & Laura & Ricardo \\
\hline Idade & 20 anos & 21 anos \\
\hline $\begin{array}{l}\text { Já ministrou aulas de Inglês? } \\
\text { Quanto tempo }\end{array}$ & Sim, oito meses & Não \\
\hline $\begin{array}{l}\text { Cursou o Ensino Básico em } \\
\text { escola particular ou pública? }\end{array}$ & $\begin{array}{c}\text { Fundamental: } \\
\text { particular } \\
\text { Médio: pública } \\
\text { Sim, um ano }\end{array}$ & Pública \\
\hline $\begin{array}{l}\text { Já fez curso de Inglês em escola } \\
\text { de idiomas? }\end{array}$ & \begin{tabular}{c} 
A escrita \\
\hline $\begin{array}{l}\text { Qual conteúdo de Inglês mais } \\
\text { gosta ou gostaria de ensinar? }\end{array}$
\end{tabular} & $\begin{array}{c}\text { Falar sobre a } \\
\text { língua }\end{array}$ \\
\hline
\end{tabular}

Fonte: elaborado pelas autoras

Apesar de trabalharmos com apenas dois participantes, para podermos conseguir atingir os objetivos propostos inicialmente, reconhecemos a importância e, principalmente, a participação fundamental de todos os demais envolvidos na constituição e na formação da CdP. 


\section{Análise e discussão dos dados}

Ricardo, no excerto 1, que segue abaixo, mostra-nos o que achou de positivo na sua participação na $\mathrm{CdP}$, concebendo-a como forma de enfrentar os desafios da tecnologia e, segundo sua própria narrativa, agora não pode viver mais sem "esse universo digital". Ele nos apresenta uma especificidade da plataforma Moodle, que é se colocar "como um espaço institucional", como um ambiente limitado ao contexto educacional, no qual ainda perpetua uma assimetria de posição entre o professor formador/professor aprendiz, aluno/aluno e professor aprendiz/professor regente da escola campo. O primeiro páreo, por exemplo, ficou marcado pela presença implícita e/ou explícita do professor formador como "avaliador" das colocações, das discussões e das negociações postadas. Na entrevista, nas linhas 7, 8, 9, 10, 11 e 12, quando Ricardo compara o Moodle com a rede social Facebook, mais uma vez ele potencializa sua percepção em relação à CdP como algo criado institucionalmente para julgar, avaliar ou até mesmo reprovar o professor aprendiz, conduzindo-o a uma relativa desmotivação em participar das interações.

\section{Excerto 1}

(1)Pesquisadora: e o moodle? O que influenciou pra você, pontos (2)positivos e pontos negativos do moodle?

(3)Ricardo: ponto positivo, eu acho que ele força você a encarar o (4)universo digital que tá aí que é uma... que pra mim eu não consigo me ver (5)mais sem esse universo digital. Negativo, eu acho que é porque é assim: o (6)moodle é um espaço institucional NÉ, não chega a ser negativo, eu acho (7)que é muito mais questão de limitação mesmo dele NÉ, porque o espaço (8)digital, que é por a gente pegar o exemplo do facebook, que todo mundo (9)fala, todo mundo se expõem, ninguém tem medo de dizer o que pensa no (10)facebook ninguém tem medo, até porque lá só tem a ferramenta curtir, (11)ninguém pode não curtir o que você fala, a pessoa pode até comentar e (12)tal mas, não curtir não tem como, ninguém tem como te reprovar, no (13)moodle tem. No moodle você pode ter uma nota descontada se sua fala (14)for negativa (a 
Discurso e relações de poder na (re)construção da identidade...

entrevistadora ajuda a concluir a fala) se ela for (15)considerada inadequada, você, você...

(16)Pesquisadora: mas quem te reprovaria? Ninguém...

(17)Ricardo: tem atribuição de nota NÉ no moodle. Então se você não (18)participa você, mesmo que não, não, não perca, você deixa de ganhar na (19)nota por não participar do moodle. Então a diferença de motivação pra (20)escrever no moodle é que eu acho é é a deficiência.

(21)Pesquisadora: pois é, senti que você então não participou do moodle (22)esse semestre também, Foi falta de motivação? (23)Ricardo: não. Foi porque por exemplo, eu até entrava no moodle e eu (24)tava vendo assuntos muito batidos, aí pra não ficar repetindo a mesma (25)coisa eu acho que não faz sentido. (26)Pesquisadora: você entrou esse semestre?

(27)Ricardo: entrei, andei lendo algumas postagens, não nos... até no seu eu (28)entrei uma vez pra poder ler pôsteres, mas não vi nada novo, é que eu (29)fico recebendo na minha caixa de e-mail, as postagens.

(Entrevista final, dezembro de 2011).

Contextualizando a fala de Ricardo para melhor compreensão do leitor, na idealização e criação da $\mathrm{CdP}$, foi abordada, com todos os participantes, a questão da liberdade que teriam em participar ou não das discussões postadas, sendo que os participantes poderiam, inclusive, escolher ou até mesmo direcionar o fio condutor das discussões, haja vista que estes seriam alguns dos fatores essenciais para que a plataforma se configurasse em uma $\mathrm{CdP}$, segundo as considerações de Wenger (1998), isto é, eles se sentiriam motivados e engajados, mutuamente, a partir de um assunto ou tema de interesse ou paixão em comum ao grupo, o que os levaria a sentir o desejo de pertencimento àquela comunidade com a qual se identificariam.

Observamos pela fala de Ricardo que essa tentativa "de recuperar a motivação" fracassou, e teve efeito contrário, pois, como ele afirma: "Então a diferença de motivação pra escrever no Moodle é que eu acho é a deficiência [ganhar ou deixar de ganhar nota]". No entanto, acreditamos que devido às dificuldades enfrentadas com a CdP no contexto de criação, "distorcemos", ou melhor, nos afastamos um pouco da visão de CdP "ideal” para formação de professores, mas, 
por outro lado, também entendemos que a tornamos mais real, haja vista que os desafios, as dificuldades e os problemas acontecem em qualquer ambiente de formação. Na sequência, linhas 23 a 25 do excerto 1, Ricardo pontua outro fator que o desmotivou a participar das discussões na plataforma, declarando que os assuntos estavam "muito batidos", e esta afirmação nos conduz a uma reflexão mais crítica quanto ao gerenciamento e à manutenção de $\mathrm{CdPs}$, nas quais a mediação teria de entrar no compasso e na dinamicidade inerentes às interações mediadas virtualmente.

Apesar de na CdP os membros se autosselecionarem, conforme apontam Wenger e Snyder (2000), entendemos que a CdP tende a sofrer transformações e a ganhar novos contornos tendo em vista a especificidade da área em que é utilizada, uma vez que a versão proposta pelos autores foi pensada em um ambiente empresarial, campo de estudo de Wenger (1998). No âmbito escolar e acadêmico, ao pensarmos na disciplina ministrada por um professor e na proposta sugerida por ele para alunos que não haviam participado de atividades como essa anteriormente, a figura do professor mediador tornou-se indispensável na criação da comunidade, na mediação das interações e no gerenciamento do processo. A mediação do professor foi essencial até mesmo na busca por uma maior simetria entre aluno e professor, ao assumir um papel de mediador do processo e oferecer suporte necessário que permitisse e instigasse a negociação entre os participantes em um processo de reflexão, de colaboração, de participação ativa e de contribuição mútua.

Baseando-nos na definição e nas características da CdP, apontadas por Wenger (1998), bem como considerando as especificidades da área investigada, possibilitamos com o desenvolvimento deste estudo o desenvolvimento de um lugar comum para que os professores em formação inicial pudessem construir conhecimento, discutir formal e informalmente sobre ideias, perspectivas e práticas de interesse comum, compartilhar problemas, experiências e preocupações na e com a sala de aula de LE, vivenciadas na escola campo de estágio e/ou compartilharem uma paixão em comum, como a de se sentirem ou não professores de LE. Diante de tais finalidades e características que configuraram a CdP deste estudo, e tendo por base o conceito trazido por Wenger (1998) e Clarke (2008), entendemos que mesmo com nossas especificidades 
locais, que influíram na instauração e na criação de nossa Comunidade na plataforma Moodle, o espaço virtual configurou-se numa Comunidade de Prática voltada para a educação e a formação de professores, a qual abarcou as três dimensões propostas por Wenger (1998), fundamentais para a Comunidade: compromisso/engajamento mútuo, empreendimento partilhado e repertório compartilhado.

Pontuando as relações de poder que se estabeleceram nas plataformas, nas linhas 13 e 14, Ricardo explicita: "No Moodle você pode ter uma nota descontada se sua fala for negativa". Isso nos permite afirmar que ele prefere omitir-se nos posicionamentos, ou ainda, da sua posição de fala, como aprendiz, com medo ou receio da reprovação do professor e ou dos colegas interagentes na CdP. Nas interações da CdP, registradas no Moddle, também verificamos traços ou indicadores significativos pontuais que nos levaram a identificar a presença de identidade de professor/aprendiz preocupados ainda com a avaliação e/ou com a presença onipresente do professor formador nas discussões. Por exemplo, para Ricardo expressar uma opinião sobre $O$ que é ser professor de $L E$ - tema instigador de discussão proposto pelo professor formador na criação da plataforma -, ele precisou se apoiar em um discurso científico (CORACINI, 2003; BARBOSA, 2012) ou em discursos acadêmicos proferidos por um mestre da instituição formadora, que apresenta o papel de detentor do conhecimento, gate keeper (NORTON, 2000; 2001), isto é, mais uma vez se faz presente a relação de poder do professor em relação ao aprendiz, que precisa agradar, ou ainda, ser aprovado pelo professor em seu discurso, como podemos ver no excerto extraído da plataforma:

\section{Excerto 2}

(1)Ricardo: só aprendemos uma segunda língua em função de interesses (2)políticos ou econômicos, em alguns casos interesses particulares (3)como curiosidade ou simples simpatia pelo idioma/cultura (4)estrangeira. Como muito bem ressaltou a professora Patrícia, o (5)professor de LE deve mediar o contato dos alunos com esse "outro (6)mundo" de maneira consciente, reconhecendo os motivos e interesses (7)envolvidos no uso (ou não uso) de determinadas línguas. O que é ser (8)professor de LE? (CdP - quinta, 12 maio 2011, 22h46min - ênfase nossa). 
Nas linhas 1 e 2, Ricardo, em seu discurso, condiciona a aprendizagem de uma segunda língua "somente" a questões de interesse político ou econômico. Neste caso, entendemos que Ricardo externaliza sua preocupação em adquirir um bem cultural, ou seja, aprender uma segunda língua como forma de investimento e ascensão em sua carreira profissional como professor de línguas. A outra participante, Laura, também se pronuncia por meio de discursos acadêmicos/científicos proferidos por sua professora formadora Patrícia era a professora de Estágio Supervisionado da turma de Laura e Ricardo -, concebendo-a também como uma gate-keeper para dar sua opinião sobre o que é ser professor de LE, deixando, pois, nesse momento, vigorar sua identidade de aluno/aprendiz preocupada, de certa forma, com a avaliação da professora quanto à sua postagem, e, além disso, começa seu discurso na plataforma direcionando-se à professora e não aos seus colegas da comunidade, como se pode ver a seguir: "Olá professora! perdão pela demora...". Como se pode observar, a participante justifica seu atraso em participar da discussão naquela plataforma devido à "correria" que a impediu de participar antes. In verbis:

\section{Excerto 3}

(1)Laura: Olá professora! Perdão pela demora... foi a correria que me (2)impediu de participar antes! rsrsrs. Bem, eu gostei muito do que a (3)professora Patrícia disse. $\mathrm{O}$ professor deve preparar o aluno para agir (4)com competência e criatividade no sistema de globalização, mas (5)também precisa ir além do aspecto puramente linguístico, fazendo (6)isso através de discussões que põem em cheque a cultura e os fatores (7)políticos que toda língua carrega.

(8) $O$ que é ser professor de LE? (CdP - domingo, 15 maio de 2011 - ênfase nossa).

Outro tipo de posicionamento de poder que surgiu nas interações da CdP é a relação de inferioridade do professor aprendiz em detrimento da posição do professor regente na escola campo em 
Discurso e relações de poder na (re)construção da identidade...

que foram realizadas as aulas práticas de estágio. Vejamos no excerto 4 a seguir:

\section{Excerto 4}

(1)Laura: Eles gostam de Justin Bieber, mas não querem entender a letra (2)que cantam! Enfim, o que o professor pode fazer pra melhorar isso?! (3)Eu acredito realmente acredito! que o professor tem condições de (4)chamar a atenção dos alunos em relação à língua inglesa. Nós, pobres (5)estagiários, passamos pouco tempo com os alunos mas tempo suficiente para ver que os alunos não aprendem na escola que precisam do inglês não somente para passar de ano mas para não serem alienados no mundo que fala inglês!! (CdP - segunda, 22 novembro 2010 - ênfase nossa).

Quando Laura, na sua identidade de professor em formação ou, ainda, de professor aprendiz, declara : "Nós, pobres estagiários, passamos pouco tempo com os alunos", reconhece sua posição assimétrica no que toca ao poder (NORTON, 2000) em relação ao professor regente, concursado e responsável pela turma em que ela ministrou suas aulas práticas. Laura sabe que, além das poucas horas em que teve contato com os alunos da escola campo, também não tem autonomia suficiente para avaliar ou promover mudanças significativas nas atitudes e na consciência desses alunos. No entanto, no excerto 5, que segue, Laura reconhece em sua imagem projetada de identidade de professora de línguas (URZÚA; VÁSQUEZ, 2008) seu poder de ser o centro das atenções na sala de aula e, consequentemente, influenciar seus alunos com suas opiniões, crenças, filosofias, concepções e ideologias, e com isso transformá-los em cidadãos mais críticos e comprometidos com a educação do país, como podemos ver a seguir:

\section{Excerto 5}

(1)Laura: Dar aulas é apaixonante, não há como descrever a sensação de (2)se sentir o "centro das atenções" na sala, em ser aquela pessoa que, (3)de alguma forma, poderá influenciar os alunos desde o momento (4)em que eles 
entram em nossa sala. Este é o meu maior desejo agora, (5)influenciá-los a serem cidadãos críticos e comprometidos com a (6)educação do nosso país (CdP segunda, 5 de dezembro de 2011, 16h30min - ênfase nossa).

Torna-se importante, portanto, perceber como esse processo de (re)posições reais elou imaginárias de poder durante as práticas sociais de linguagem influenciam em suas (re)construções identitárias profissionais. A prática e os discursos de Ricardo e Laura revelam concepções assimétricas que perpetuam práticas, posições e relações de poder entre o aluno estagiário em processo de formação inicial e o professor formador, o professor aprendiz e o professor regente da escola campo. A relação de poder e a assimetria estão presentes desde a construção de seus conhecimentos científicos/teóricos proferidos pelos alunos até a postura de participação em atividades práticas, como na CdP, que são motivadas e/ou desmotivadas pela concepção de um ambiente limitado ao contexto educacional e avaliativa do formador, apesar de uma proposta de aprendizagem e formação predominantemente colaborativa. Nas relações de poder é que compreendemos as (re)negociações identitárias e os deslocamentos de suas identidades de aprendizes para a identidade de professores de língua estrangeira. E, como aponta Norton (2000), essas relações de poder também nos instigam a refletir sobre a necessidade de se (re)pensar a maneira como elas vêm sendo abordadas na academia ou fora dela, como, por exemplo, em CdPs, ou ainda como essas relações de poder, nos espaços discursivos formais elou informais, virtuais elou presenciais de formação de professores, influenciam nas (re)construções de suas identidades profissionais. Acrescentamos a essas reflexões o papel da instituição escolar e do professor formador no contexto educacional e na formação desses futuros professores.

\section{Considerações finais}

Conforme o exposto, acreditamos que uma CdP, para e no contexto educacional, pode também apresentar posicionamentos, deslocamentos e negociações de poder entre seus membros 
simultaneamente às negociações e às (re)construções indentitárias. Consideramos importante também que haja investimento na formação profissional de professores que estejam ingressando na experiência com e na docência, pois eles estão investindo em suas próprias identidades de professores de línguas. E para que os futuros professores de língua possam posicionar-se significativamente nesse idioma, acreditamos que eles precisam refletir sobre esse movimento e os re-posicionamentos de posições de poder imbuídas nas práticas discursivas tanto em salas de aula de línguas quanto em ambientes virtuais de interação.

De uma perspectiva holística, em relação às interações realizadas na $\mathrm{CdP}$ e nas falas transcritas da entrevista, mostradas nos excertos deste artigo, evidenciamos posicionamentos de poder nas interações, a saber: professor formador e professor em formação, professor estagiário e professor regente nas escolas campo e entre eles mesmos, ou seja, entre os colegas interagentes da comunidade em formação inicial. Acreditamos que uma forma de ajudá-los a se (re)posicionarem e assumirem seus espaços dentro dessas relações de poder é mostrando-lhes, principalmente, a relevância da linguagem e desses posicionamentos e negociações discursivas para o desenvolvimento e o investimento em suas identidades de professores de língua estrangeira, o que justifica a articulação de uma proposta de reconceitualização dos projetos pedagógicos dos cursos de formação de professores de língua com a inclusão de disciplinas que tematizem esse complexo processo de (re)construção identitária, por intermédio do discurso e das relações de poder nele instauradas, conforme abordamos na introdução deste trabalho.

Recomendamos ainda direcionarmos nossos olhares a partir de uma perspectiva mais crítica relacionada aos usos das novas tecnologias da informação e da comunicação, como no caso da plataforma Moodle, utilizada como ambiente para constituição da CdP, em diversos contextos de línguas e de formação de professores, pois muitas vezes ainda se acredita que o uso dos recursos tecnológicos por si só é benéfico ao processo de ensino e aprendizagem, ou, ainda, temse a crença de que ambientes virtuais são espaços que contribuem para "a formação de CdPs e, consequentemente, para os professoresaprendizes, sem que sejam consideradas outras questões tão pertinentes a esse ambiente e relacionadas a essa prática que são fundamentais 
para compreender melhor como se dá a formação nesse meio e para atuar nesse meio" (BEDRAN, 2012, p. 260). Ademais, sugerimos que, juntamente com o direcionamento para uma perspectiva mais crítica e reflexiva sobre o uso dos recursos tecnológicos, haja também uma postura mais investigativa para novos contextos que propiciem formação colaborativa, como a $\mathrm{CdP}$ desta pesquisa.

\section{Referências}

ANDRÉ, Marli E. D. A. Etnografia da prática escolar. Campinas: Papirus Editora, 1995.

A pesquisa sobre formação de professores no Brasil: 1990/1998. In: CANDAU, Vera Maria (Org.) Ensinar e aprender: sujeitos, saberes e pesquisa. Rio de Janeiro: DP\&A, 2000. p. 257-66.

ALSUP, Janet. Teacher identity discourses: negotiating personal and professional spaces. Mahwah, New Jersey: Lawrence Erlbaum Associates, 2006.

BARBOSA, Selma M. A. D. Escrita em ambiente virtual na formação inicial do professor de língua estrangeira. In: SILVA, Wagner. R. (Org.). Letramento do professor em formação inicial: interdisciplinaridade no estágio supervisionado da licenciatura. Campinas: Pontes, 2012. p. 165-180.

BEDRAN, Patrícia F. A formação inicial do professor de línguas no e para o contexto virtual e a construção de comunidades de prática. 306f. Tese (Doutorado em Estudos Linguísticos) - Instituto de Biociências, Letras e Ciências Exatas, Universidade Estadual Paulista Júlio de Mesquita Filho, São José do Rio Preto, 2012.

BUCKLEY, Sheryl; DU TOIT, Adeline. Academics leave your ivory tower: form communities of practice. Educational Studies, v. 36, n. 5, p. 493-503, 2010.

BURNS, Anne. Collaborative action research for English language teachers. New York: Cambridge University Press, 1999. 
Discurso e relações de poder na (re)construção da identidade...

CLARKE, Matthew. Language teacher identities: co-constructing discourse and community. Clevedon: Multilingual Matters, 2008.

CORACINI, Maria José R. F. Língua estrangeira e língua materna: uma questão de sujeito e identidade. In: CORACINI, Maria José R. F. (Org.). Identidade e discurso: (des)construindo subjetividades. Campinas: Unicamp, 2003. p. 139-59.

CUMMINS, Jim. Negotiating identities. Education for empowerment in a diverse society. Ontario: California Association for Bilingual Education, 1996.

DUFF, Patricia; UCHIDA, Yoshikazu. The negotiation of teachers' sociocultural identities and practices in postsecondary EFL classrooms. TESOL Quarterly, v. 31, n. 3, p. 451-86, 1998.

ERICKSON, Frederick. Qualitative methods in research on teaching. In: WITTROCK, Merlin C. (Ed.). Handbook of research teaching. New York: MacMillan Publishing Co, 1986.

FAIRCLOUGH, Norman. Critical discourse analysis and the marketization of public discourse:the universities. Discourse and Society, v. 4, n. 2, p. 133-168, 1993.

FETTERMAN, David M. Etnography: step by step. London: Sage Publications, 1998.

FOUCAULT, Michel. Microfísica do poder. Organização, introdução e revisão técnica de Roberto Machado. Rio de Janeiro: Graal, 1979.

FREIRE, Paulo. Pedagogia do oprimido. Rio de Janeiro: Paz e Terra, 1970.

GEE, James P. An introduction to discourse analysis: theory and method. London: Routledge, 1999. 
GIMENEZ, Telma; CAPRIOLI, Barbara. Relações de poder em comunidades de prática: um estudo com professoras de inglês. Metalinguagens, v. 1, p. 49-65, 2014.

GIROUX, Henry A. Teachers as intellectuals: toward a critical pedagogy of learning. Granby: Bergin\&Garvey, 1988.

- Cruzando as fronteiras do discurso educacional: novas políticas em educação. Porto Alegre: Artes Médicas, 1999.

LEFFA, Vilson. Identidade e aprendizagem de línguas. In: SILVA, Kleber A. et al. (Org.). A formação de professores de línguas: novos olhares. Vol II. Campinas: Pontes Editores, 2013. p. 51-81.

LEUNG, Constant; HARRIS, Roxy; RAMPTON, Ben. The idealized native speaker, reified ethnicities and classromm realities. TESOL Quarterly, v. 31, n. 3, p. 543-60, 1997.

MANTERO, Miguel. Identity and second language learning: culture, inquiry, and dialogic activity in educational contexts. North Carolina: Information Age Publishing (IAP), Charlotte, 2007. p. 1-12.

MEDEIROS, Leila L. de. Comunidades virtuais de educadores: um espaço virtual de construção da prática docente. Dissertação (Mestrado em Educação) - Faculdade de Educação, Universidade Federal Fluminense, Niterói, 2005.

MOITA LOPES, Luiz Paulo. Oficina de Linguística Aplicada. Campinas: Mercado de Letras, 1996.

(Org.) Por uma Linguística Aplicada indisciplinar. São Paulo: Parábola Editorial, 2006. 279 p.

MORGAN, Brian. Identity and intonation: linking dynamic processes in the ESL classroom. TESOL Quarterly, v. 31, n. 3, p. 431-50, 1997.

NORTON, Bonny. Identity and language learning: gender, ethnicity and educational change. Edinburgh: Pearson Education, 2000. 
Discurso e relações de poder na (re)construção da identidade...

NUNAN, David. Research methods in language learning. Cambridge: University Press, 1992.

PINO-SILVA, Juan; MAYORA, Carlos A. English teachers' moderating and participating in CoPs. System, v. 38, p. 262-271, 2010.

REIS, Davi S. I'm not alone: empowering non-native English-speaking teachers to challenge the Native Speaker Myth. In: JOHNSON, Karen. E.; GOLOMBEK, Paula. R. (Ed.). Research on second language teacher education: a sociocultural perspective on professional development. New York and London: Routledge, 2011. p. 31-49.

SCHECTER, Sandra; BAYLEY, Robert. Language socialization practices and cultural identity: case studies of Mexican descent families in California and Texas. TESOL Quarterly, v. 31, n. 3, p. 51342, 1997.

SIMON, Roger. Empowerment as pedagogy of possibility. Language Arts, v. 64, p. 370-383, 1987.

- Teaching against the grain: texts for a pedagogy of possibility. New York: Bergin; Garvey, 1992.

THESEN, Lucia. Voices, discourse and transition. TESOL Quarterly, v. 31, n. 3, p. 487-512, 1997.

TRENT, John G.; LIM, Ching Y. Teacher identity construction in school-university partnership: discourse and practice. Teaching and Teacher Education Journal, Hong Kong, Elsevier, v. 24, n. 26, p. 1609-1618, 2010.

URZÚA, Alfredo; VÁSQUEZ, Camilla. Reflection and professional identity in teachers' future-oriented discourse. Teaching and Teacher Education Journal, University of Texas, Elsevier, v. 24, n. 24, p. 19351946, 2008.

VARGHESE, Manka M. et al. Theorizing language teacher identity: three perspectives and beyond. Journal of Language, Identity, and Education, v. 6, n. 4, p. 21-44, 2005. 
WENGER, Étienne. Communities of practice: learning, meaning, and identity. Cambridge: Cambridge University Press, 1998.

; SNYDER, William M. Communities of practice: the organizational frontier. Harvard Business Review. Jan./fev. 2000. Disponível em: <http://www.ewenger.com/pub/index.htm>. Acesso em: 13 jul. 2010.

. MCDERMOTT, Richard; SNYDER, William M. A Guiding to managing knowledge: cultivating communities of practice. Boston: Harvard Business School Press, 2002.

Recebido em: 22/08/15

Aceito em: 20/11/15

Title: Discourse and power relations in the (re)construction of preservice language teachers' identity in a community of practice in the digital environment 